Supporting Information

\title{
Origin of Bond Elongation in a Uranium(IV) Cis-Bis(imido) Complex
}

Tyler S. Collins, ${ }^{1}$ Cristian Celis-Barros, ${ }^{2}$ María J. Beltrán-Leiva, ${ }^{2}$ Nickolas H. Anderson, ${ }^{1}$ Matthias Zeller, ${ }^{1}$ Thomas Albrecht-Schönzart, ${ }^{2}$ and Suzanne C. Bart ${ }^{1 *}$

${ }^{1}$ H.C. Brown Laboratory, Department of Chemistry, Purdue University, West Lafayette, IN 47907 (USA)

${ }^{2}$ Department of Chemistry and Biochemistry, Florida State University, Tallahassee, FL 32306 (USA)

Email: sbart@purdue.edu 


\section{Table of Contents:}

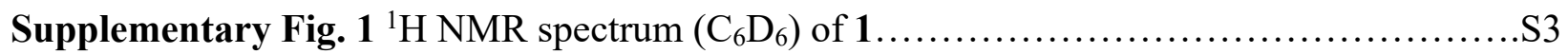

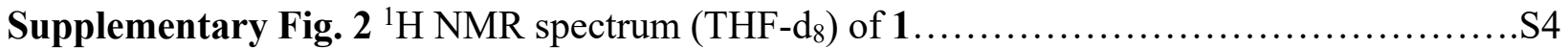

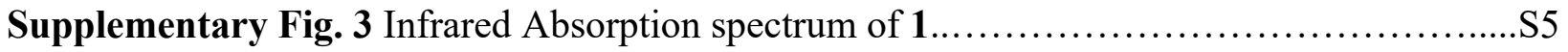

Supplementary Fig. 4 Electronic Absorption spectrum of 1 ............................... 6

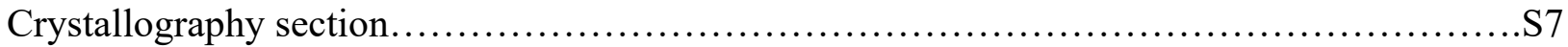

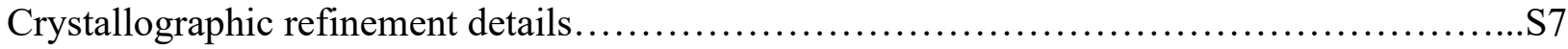

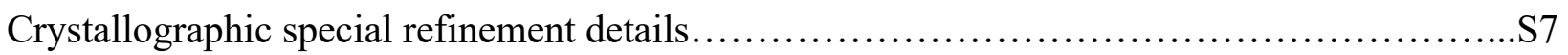

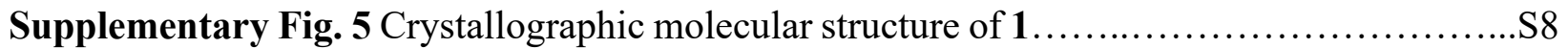

Supplementary Table 1. Selected geometric parameters for $1 \ldots \ldots \ldots \ldots \ldots \ldots \ldots \ldots \ldots \ldots . . .59$

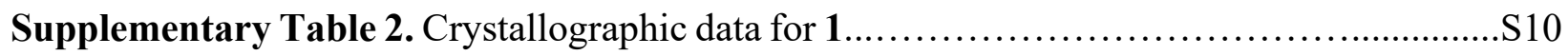

Supplementary Fig. 6 Crystallographic molecular structure of $\mathrm{UCl}_{2}(\mathrm{NDIPP})_{2}(\mathrm{THF})_{2} \ldots \ldots \ldots . \mathrm{S} 11$

Supplementary Table 3. Crystallographic data for $\mathrm{UCl}_{2}(\mathrm{NDIPP})_{2}(\mathrm{THF})_{2} \ldots \ldots \ldots \ldots \ldots \ldots \ldots \mathrm{S} 12$

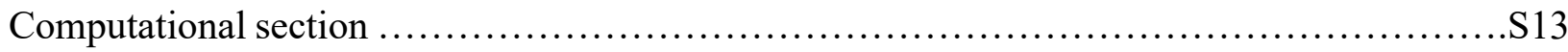

Additional Discussion................................................................

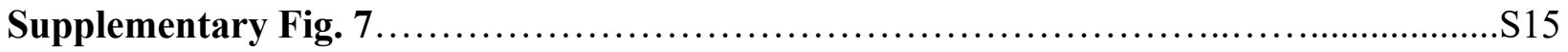

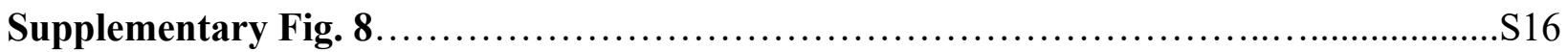

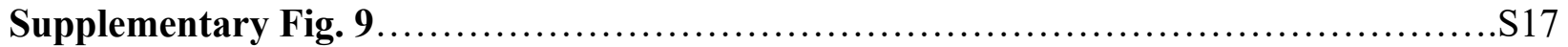

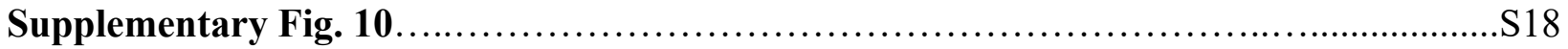

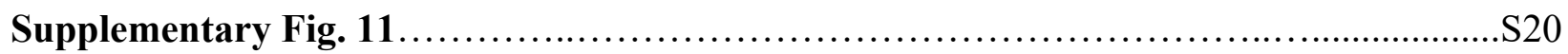

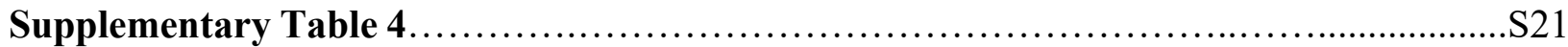

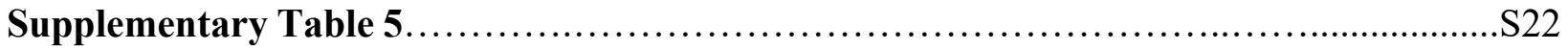

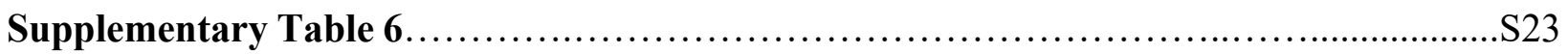

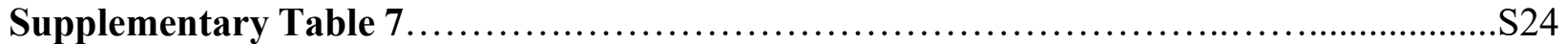

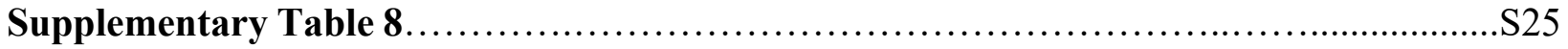

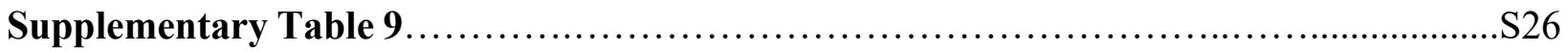

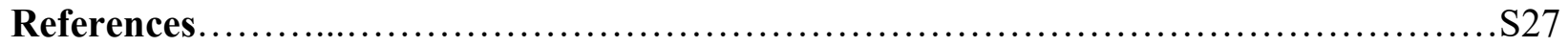




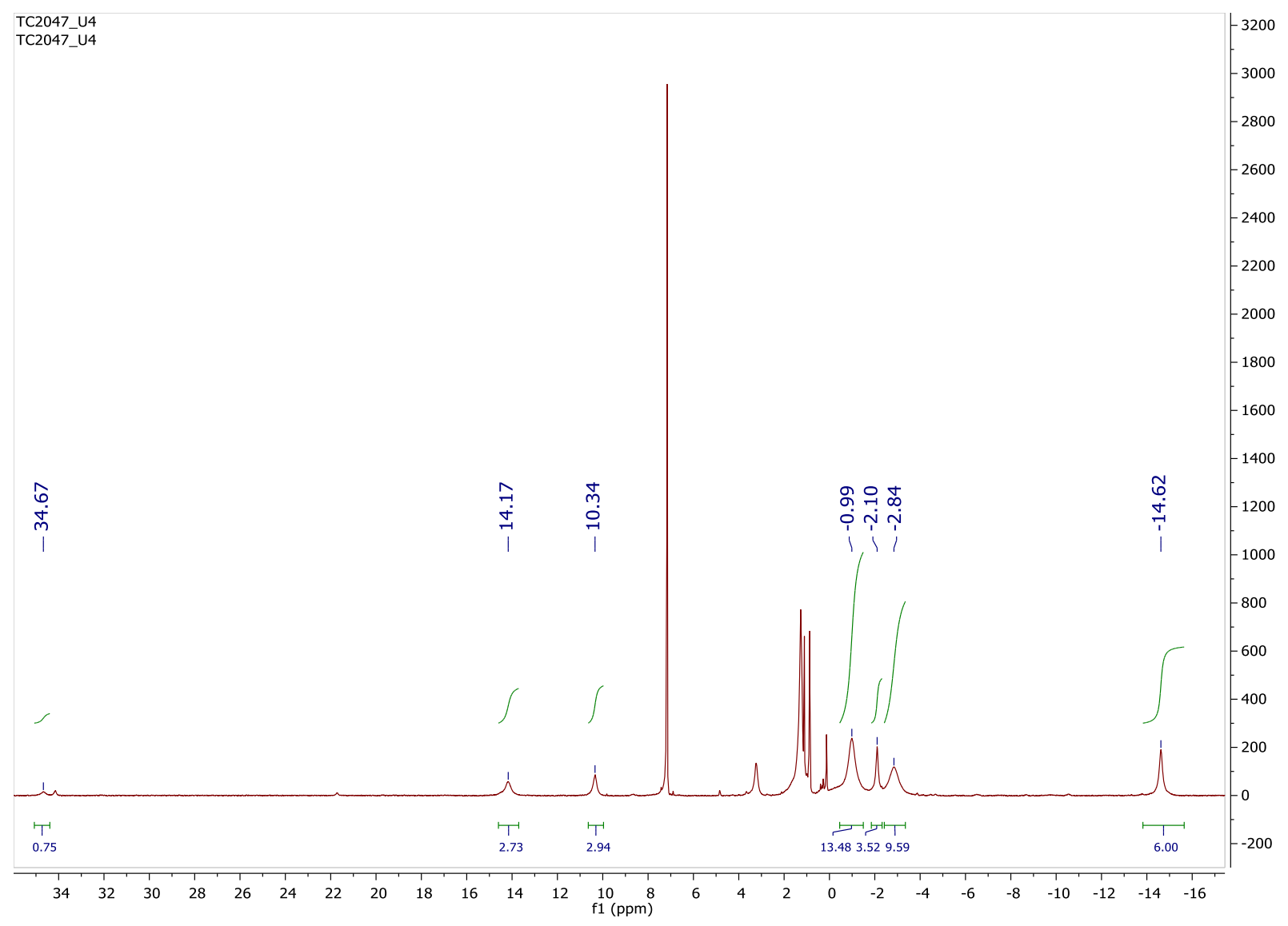

Supplementary Fig. 1. ${ }^{1} \mathrm{H}$ NMR $\left(\mathrm{C}_{6} \mathrm{D}_{6} 25^{\circ} \mathrm{C}\right)$ spectrum of $\mathbf{1}$. 


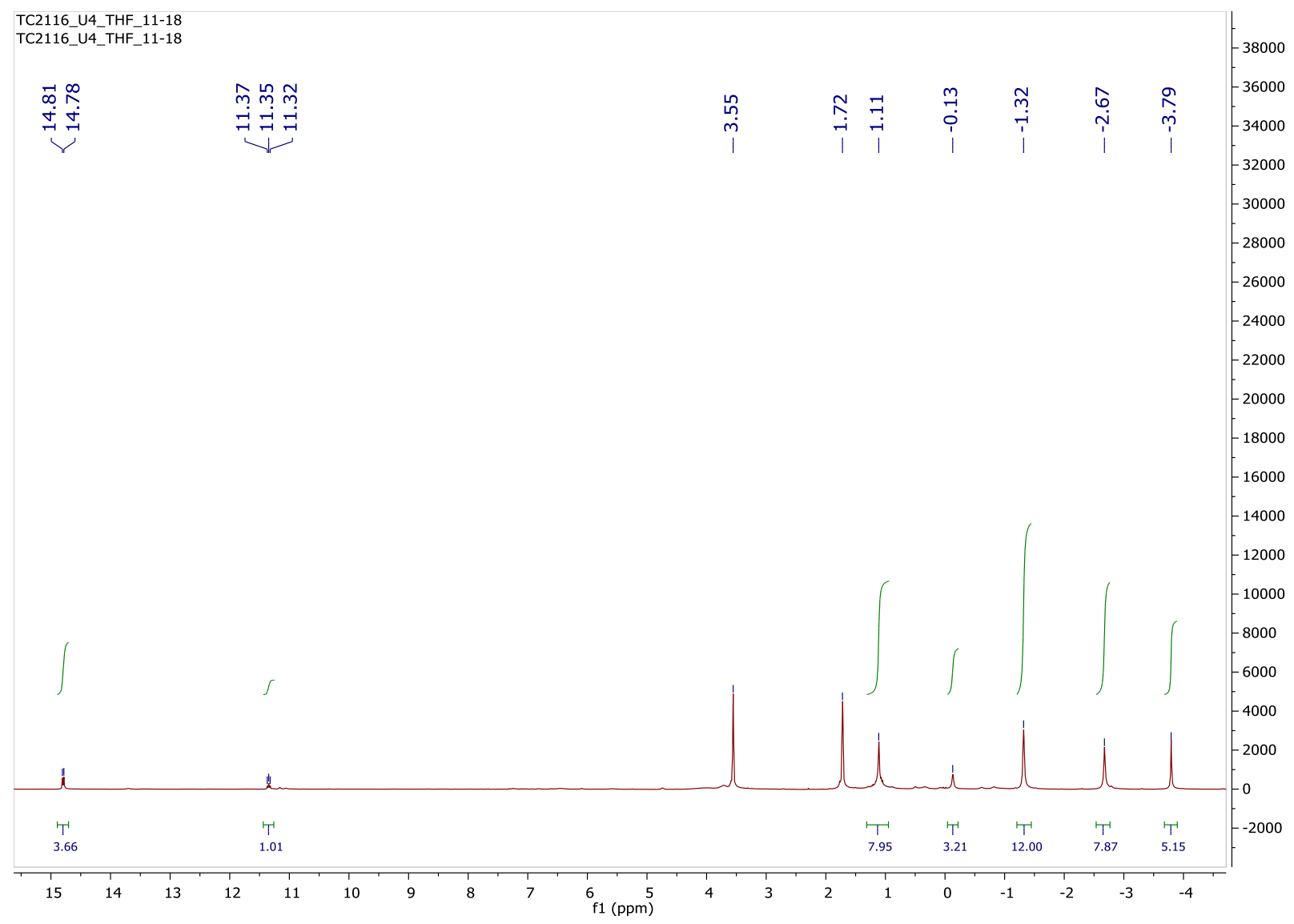

Supplementary Fig 2. ${ }^{1} \mathrm{H}$ NMR (THF-d $\left.82{ }^{\circ} \mathrm{C}\right)$ spectrum of 1. 


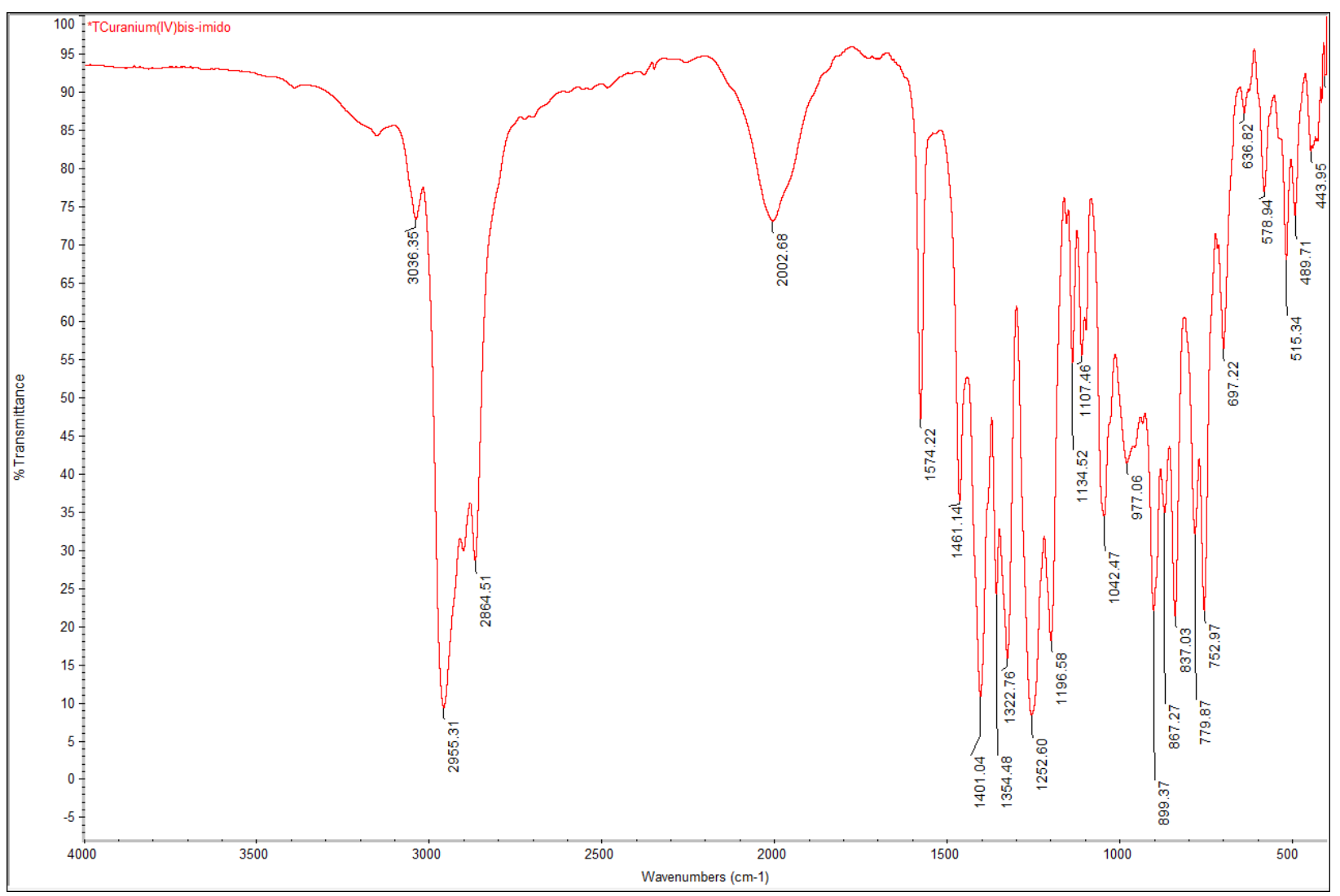

Supplementary Fig. 3. IR spectrum of $\mathbf{1}$. 


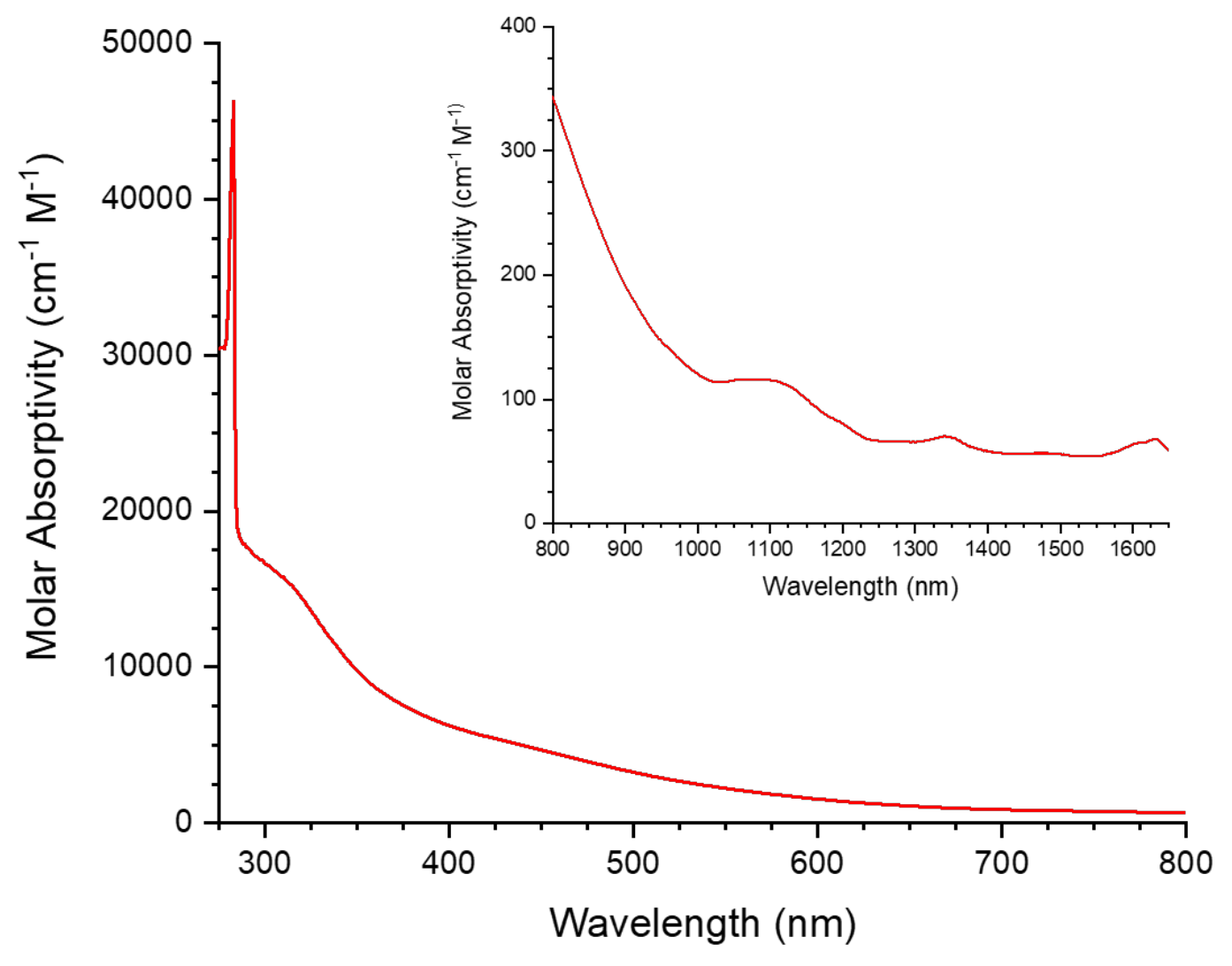

Supplementary Fig 4. Electronic absorption spectroscopy of 1 recorded at ambient temperature in toluene. 


\section{Crystallography Section}

\section{Refinement Details}

Data were collected, reflections were indexed and processed, and the files scaled and corrected for absorption using APEX3. ${ }^{1}$ The space group was assigned and the structure was solved by direct methods using XPREP within the SHELXTL suite of programs ${ }^{2}$ and refined by full matrix least squares against $F^{2}$ with all reflections using Shelx $12018^{3}$ using the graphical interface Shelxle. ${ }^{4} \mathrm{H}$ atoms attached to carbon were positioned geometrically and constrained to ride on their parent atoms. $\mathrm{C}-\mathrm{H}$ bond distances were constrained to $0.95 \AA$ for aromatic $\mathrm{C}-\mathrm{H}$ moieties, and to $1.00,0.99$ and $0.98 \AA$ for aliphatic $\mathrm{C}-\mathrm{H}, \mathrm{CH}_{2}$ and $\mathrm{CH}_{3}$ moieties, respectively. Methyl $\mathrm{CH} 3$ $\mathrm{H}$ atoms were allowed to rotate but not to tip to best fit the experimental electron density. The two $\mathrm{Si}-\mathrm{H}$ hydrogen atoms were placed in calculated positions, but the $\mathrm{Si}-\mathrm{H}$ bond distances were allowed to refine. The two $\mathrm{Si}-\mathrm{H}$ bond distances were restrained to be similar in length. $\mathrm{U}_{\text {iso }}(\mathrm{H})$ values were set to a multiple of $\mathrm{U}_{\mathrm{eq}}(\mathrm{C})$ with 1.5 for $\mathrm{CH}_{3}$ and 1.2 for $\mathrm{Si}-\mathrm{H}, \mathrm{C}-\mathrm{H}$, and $\mathrm{CH}_{2}$, respectively. Complete crystallographic data, in CIF format, have been deposited with the Cambridge Crystallographic Data Centre. CCDC 1997658 and 2033982 contains the supplementary crystallographic data for this paper. These data can be obtained free of charge from The Cambridge Crystallographic Data Centre via www.ccdc.cam.ac.uk/data_request/cif.

\section{Crystallographic special refinement details of 1:}

A diethyl ether moiety was refined as disordered in a general position modeling the moieties to be similar to that of a bound diethyl ether molecule. $U^{i j}$ components of ADPs for disordered atoms closer to each other than $2.0 \AA$ were restrained to be similar. Subject to these conditions the occupancy ratio refined to $0.58(3)$ to $0.42(3)$.

The two Si-H hydrogen atoms were placed in calculated positions, but the $\mathrm{Si}-\mathrm{H}$ bond distances were allowed to refine. The two $\mathrm{Si}-\mathrm{H}$ bond distances were restrained to be similar in length using a SADI command.

\section{Crystallographic special refinement details of $\mathrm{UCl}_{2}(\mathrm{NDIPP})_{2}(\mathrm{THF})_{2}$}

A metal coordinated THF molecule shows disorder with two alternative orientations. The two moieties were restrained to have similar geometries (SAME restraint in Shelxl) and the atoms involved in the disorder were restrained to have similar Uij components for their ADPs if closer to each other than 1.7 Angstroms. Subject to these conditions, the occupancies of the two moieties refined to $0.545(13)$ and $0.455(13)$. The two metal coordinated chlorine atoms did exhibit increased electron density and were refined as being disordered with iodine atoms. Due to the low prevalence of the heavier halogen positions and ADPs of chlorine and iodine atoms were constrained to be each identical. Subject to these conditions, the occupancy ratios refined to $0.8544(18)$ and 0.1456(18) for Cl1 and I1, and to 0.9458(17) and 0.0542(17) for Cl2 and I2. 


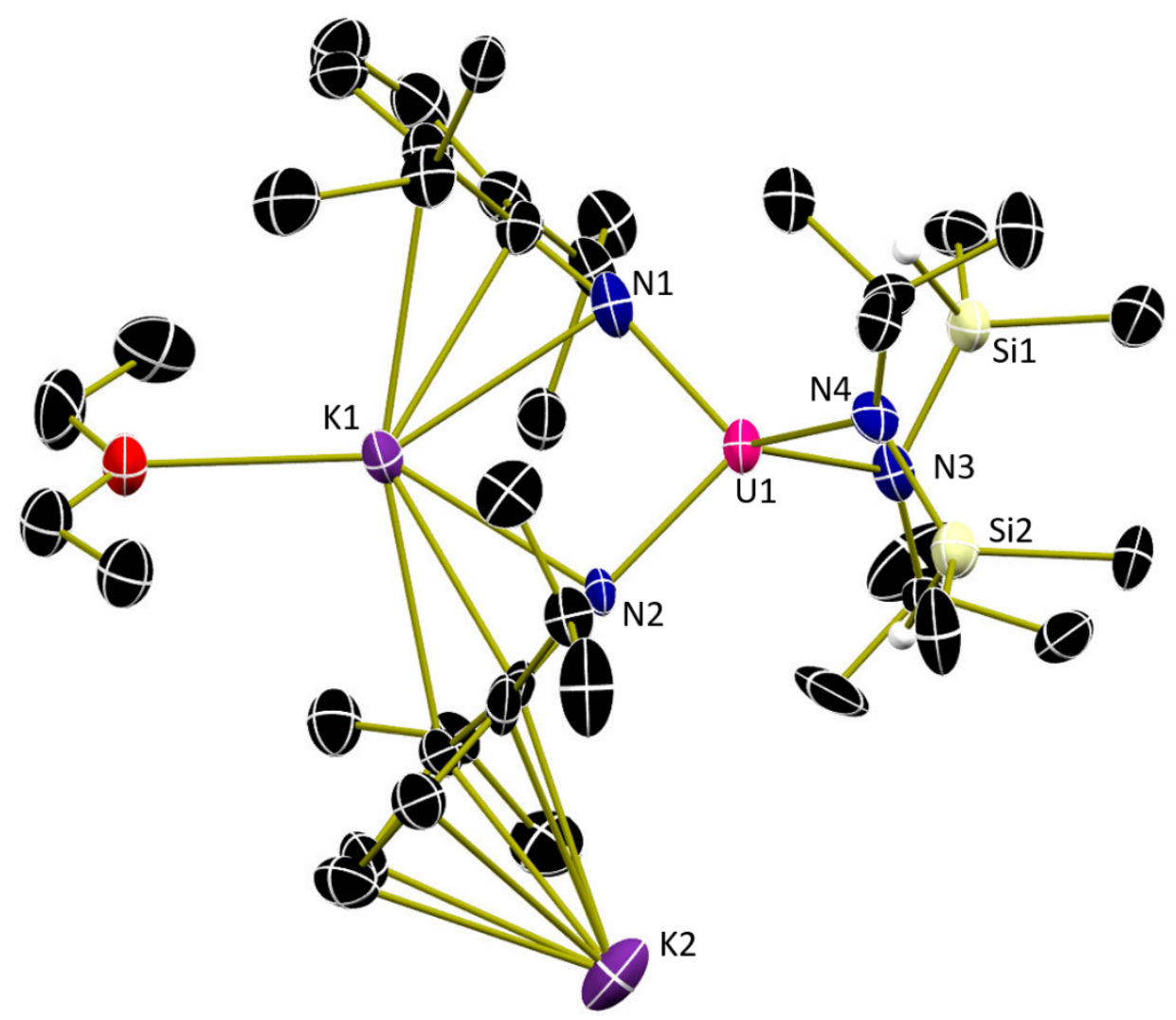

Supplementary Fig. 5. Molecular structure of $\mathbf{1}$ shown at 30\% probability ellipsoids. Selected hydrogen atoms, and disordered solvent molecule have been removed for clarity. 
Supplementary Table 1. Selected geometric parameters of $\mathbf{1}$.

\begin{tabular}{|c|c|}
\hline Atom label & Bond Distance/Angle $\left(\AA{ }^{\circ}{ }^{\circ}\right)$ \\
\hline U1-N1 & $2.069(17)$ \\
\hline U1-N2 & $2.149(11)$ \\
\hline U1-N3 & $2.365(12)$ \\
\hline U1-N4 & $2.365(14)$ \\
\hline U1-K1 & $3.7617(12)$ \\
\hline N1-U1-N2 & $95.2(3)$ \\
\hline C1-N1-U1 & $169.2(14)$ \\
\hline C13-N2-U1 & $170.2(11)$ \\
\hline
\end{tabular}


Supplementary Table 2. Tabulated Crystal Data of $\mathbf{1}$ :

\begin{tabular}{|c|c|}
\hline & TC1075_0m \\
\hline \multicolumn{2}{|l|}{ Crystal data } \\
\hline Chemical formula & $\mathrm{C}_{35} \mathrm{H}_{66} \mathrm{~N}_{4} \mathrm{SI}_{2} \mathrm{UK}_{2} \cdot\left(\mathrm{C}_{4} \mathrm{H}_{10} \mathrm{O}\right)_{2}$ \\
\hline$M_{\mathrm{r}}$ & 2147.11 \\
\hline Crystal system, space group & Monoclinic, $C c$ \\
\hline Temperature $(\mathrm{K})$ & 150 \\
\hline$a, b, c(\AA)$ & $19.6646(4), 15.0211(4), 19.9679(5)$ \\
\hline$\beta\left(^{\circ}\right)$ & $113.644(1)$ \\
\hline$V\left(\AA^{3}\right)$ & $5403.1(2)$ \\
\hline$Z$ & 2 \\
\hline Radiation type & $\mathrm{Cu} K \alpha$ \\
\hline$\mu\left(\mathrm{mm}^{-1}\right)$ & 10.52 \\
\hline Crystal size $(\mathrm{mm})$ & $0.14 \times 0.06 \times 0.06$ \\
\hline \multicolumn{2}{|l|}{ Data collection } \\
\hline Diffractometer & Bruker AXS D8 Quest CMOS diffractometer \\
\hline Absorption correction & $\begin{array}{l}\text { Multi-scan, SADABS 2016/2: Krause, L., Herbst-Irmer, R., } \\
\text { Sheldrick G.M. \& Stalke D., J. Appl. Cryst. } 48 \text { (2015) 3-10 }\end{array}$ \\
\hline$T_{\min }, T_{\max }$ & $0.084,0.233$ \\
\hline $\begin{array}{l}\text { No. of measured, independent } \\
\text { and observed }[I>2 \mathrm{~s}(I)] \\
\text { reflections }\end{array}$ & $20025,9227,8666$ \\
\hline$R_{\text {int }}$ & 0.039 \\
\hline$(\sin \theta / \lambda)_{\max }\left(\AA^{-1}\right)$ & 0.639 \\
\hline \multicolumn{2}{|l|}{ Refinement } \\
\hline$R\left[F^{2}>2 \sigma\left(F^{2}\right)\right], w R\left(F^{2}\right), S$ & $0.029,0.079,1.05$ \\
\hline No. of reflections & 9227 \\
\hline No. of parameters & 565 \\
\hline No. of restraints & 150 \\
\hline H-atom treatment & $\begin{array}{l}\mathrm{H} \text { atoms treated by a mixture of independent and } \\
\text { constrained refinement }\end{array}$ \\
\hline$\Delta \rho_{\max }, \Delta \rho_{\min }\left(\mathrm{e} \AA^{-3}\right)$ & $1.33,-0.78$ \\
\hline Absolute structure & Refined as an inversion twin. \\
\hline Absolute structure parameter & $0.503(10)$ \\
\hline
\end{tabular}

Computer programs: Apex3 v2016.9-0 (Bruker, 2016), SAINT V8.37A (Bruker, 2016),

SHELXS97 (Sheldrick, 2008), SHELXL2014/7 (Sheldrick, 2014), SHELXLE Rev714 (Hübschle et al., 2011). 


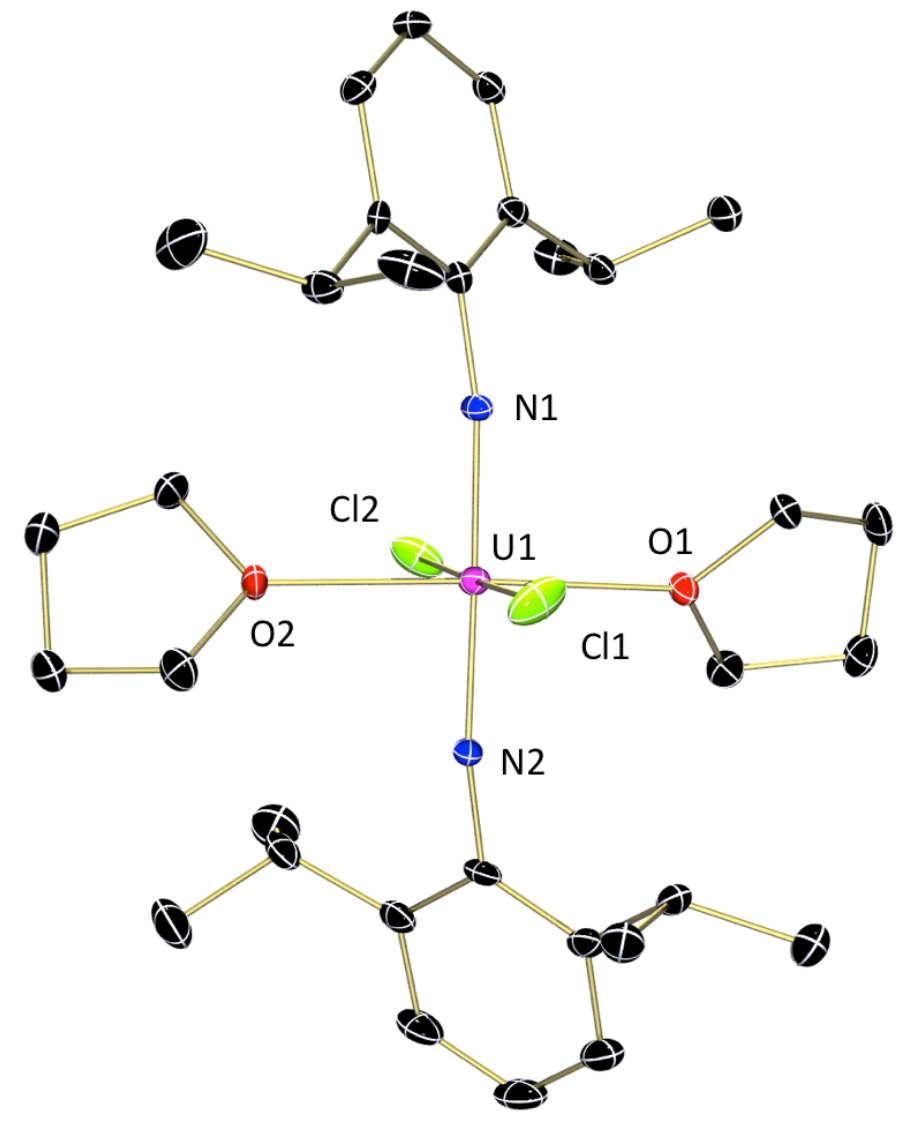

Supplemental Fig. 6. Molecular structure of $\mathrm{UCl}_{2}(\mathrm{NDIPP})_{2}(\mathrm{THF})_{2}$ shown at $30 \%$ probability ellipsoids. Selected hydrogen atoms, and disordered solvent molecule have been removed for clarity. 
Supplementary Table 3. Tabulated crystal data of $\mathrm{UCl}_{2}(\mathrm{NDIPP})_{2}(\mathrm{THF})_{2}$.

\begin{tabular}{|c|c|}
\hline & Quest15mz193_0m \\
\hline \multicolumn{2}{|l|}{ Crystal data } \\
\hline Chemical formula & $\mathrm{C}_{32} \mathrm{H}_{50} \mathrm{Cl}_{1.80} \mathrm{I}_{0.20} \mathrm{~N}_{2} \mathrm{O}_{2} \mathrm{U}$ \\
\hline$M_{\mathrm{r}}$ & 821.96 \\
\hline Crystal system, space group & Triclinic, $P^{-} 1$ \\
\hline Temperature $(\mathrm{K})$ & 100 \\
\hline$a, b, c(\AA)$ & $12.0908(6), 12.6180(5), 13.5292(6)$ \\
\hline$\alpha, \beta, \gamma\left({ }^{\circ}\right)$ & $68.896(2), 64.072(2), 85.439(2)$ \\
\hline$V\left(\AA^{3}\right)$ & $1724.29(14)$ \\
\hline$Z$ & 2 \\
\hline Radiation type & Mo $K \alpha$ \\
\hline$\mu\left(\mathrm{mm}^{-1}\right)$ & 5.05 \\
\hline Crystal size $(\mathrm{mm})$ & $0.18 \times 0.12 \times 0.06$ \\
\hline \multicolumn{2}{|l|}{ Data collection } \\
\hline Diffractometer & Bruker AXS D8 Quest CMOS diffractometer \\
\hline Absorption correction & Multi-scan, Apex2 v2014.1-1 (Bruker, 2014) \\
\hline$T_{\min }, T_{\max }$ & $0.428,0.746$ \\
\hline $\begin{array}{l}\text { No. of measured, independent and } \\
\text { observed }[I>2 \sigma(I)] \text { reflections }\end{array}$ & $37049,8519,6978$ \\
\hline$R_{\text {int }}$ & 0.068 \\
\hline$(\sin \theta / \lambda)_{\max }\left(\AA^{-1}\right)$ & 0.667 \\
\hline \multicolumn{2}{|l|}{ Refinement } \\
\hline$R\left[F^{2}>2 \sigma\left(F^{2}\right)\right], w R\left(F^{2}\right), S$ & $0.035,0.064,1.09$ \\
\hline No. of reflections & 8519 \\
\hline No. of parameters & 399 \\
\hline No. of restraints & 142 \\
\hline H-atom treatment & H-atom parameters constrained \\
\hline$\left.\Delta\rangle_{\max }, \Delta\right\rangle_{\min }\left(\mathrm{e} \AA^{-3}\right)$ & $3.80,-1.61$ \\
\hline
\end{tabular}

Computer programs: Apex2 v2014.1-1 (Bruker, 2014), SAINT V8.34A (Bruker, 2014),

SHELXS97 (Sheldrick, 2008), SHELXL2014/7 (Sheldrick, 2014), SHELXLE Rev714 (Hübschle et al., 2011). 


\section{Computational section}

\section{Additional discussion}

PES-CASSCF. As shown in Supplementary Fig. 5, the minimum of the PES was determined around 120 degrees regardless the level of theory employed in the calculation. Despite the minimal active space, $\operatorname{CAS}(2,7)$, significant deviations should not be expected in the low energy region after expanding it. According to the CASSCF natural orbital composition, as the angle is opened, an increase of the ligand contribution is observed (Supplementary Fig. 9). That is, the amount of metal $5 f$ - ligand mixing is favored. This observation is well-correlated with the splitting of the ground state obtained at CASSCF level which is retained in subsequent CASSCFPT2 and SO-PT2 calculations (Supplementary Table 8). Looking for the factors responsible for the increase in the splitting, the symmetry imposed by the ligand field seems to dominate. When the angle is smaller, most of the $5 f$ orbitals are hardly able to form symmetry adapted interactions with imido $2 p$ orbitals, therefore reducing the ligand contribution. The opposite occurs when approaching the trans-position of the imido ligands, where the $5 f_{\sigma}$ interactions become more favorable enhancing the metal-ligand interaction. Consequently, the interacting $5 f$ orbitals separate from the non-interacting ones, which is mirrored in the increased $5 f$-orbital splitting. This is also reflected in the splitting of the spin-free states belonging to the ground multiplet $\left({ }^{3} \mathrm{H}\right)$ that is afterwards reduced by inclusion of the SOC. Thus, it is important to point out the importance of the interplay between electron repulsion, ligand field, and spin-orbit coupling in the proper description of the electronic structure of actinide compounds.

U(IV)-NTSA bonds. The interaction between U(IV) and NTSA ligands is weaker than the interaction with the bis(imido) ligands, however, covalency is not negligible. As shown in Supplementary Fig. 7, $\sigma$-bonds are highly polarized (4\% U(IV)) with greater contribution of $\mathrm{U}(\mathrm{IV}) 6 d$ orbitals over the $5 f$ contribution. On the other hand, $\pi$-bonds have more $5 f$ involvement than the $\sigma$-bonds, thus the hybrid is more balanced in terms of $5 f$ and $6 d$ contributions $(50 / 50)$ which is expected for this type of bonds. A similar perspective is obtained by QTAIM, where polarization is increased by more than $10 \%$ with respect to $\mathrm{U}(\mathrm{IV})-\mathrm{N}_{\text {imido }}$ (a) and concentration of the electron density is significantly decreased (Supplementary Table 6). From the ETS-NOCV perspective, the interaction with NTSA ligands is mainly described by $\Delta \rho_{8}$ and $\Delta \rho_{9}$, whose stabilization energies are rather small compared to the rest of the deformation densities (Supplementary Fig. 9).

Energy decomposition Analysis. The energy of interaction between U(IV) and the ligands in M1 was decomposed into steric (electrostatic + Pauli) and orbital terms (Supplementary Table4). The results show that the main contribution to the total energy of interaction is the electrostatic component (76\%), while orbital (covalent/charge transfer) interactions correspond to $45 \%$. This means that covalent interactions play an important role in the nature of the chemical bond. The deformation densities $\left(\Delta \rho_{i}\right)$ associated with the bond formation are depicted in Supplementary Fig. 8 , where $\sigma$ - and $\pi$-interactions can be distinguished. According to their associated energies, $\pi$-bond formation provides most of the stability of the complex with $\Delta \rho_{1}\left(\Delta \mathrm{E}_{1}=-763.8 \mathrm{~kJ} / \mathrm{mol}\right)$ being the most important. Under this framework, it is also possible to see differences between the two U-N $\mathrm{N}_{\text {imido }}$ bonds depicted in $\Delta \rho_{5}$ and $\Delta \rho_{6}$, the former being $\sim 30 \mathrm{~kJ} / \mathrm{mol}$ more stable than 
the latter. Although, this picture seems to be clear, the lack of correlation makes this approach more qualitative than quantitative.

\section{QTAIM and electron correlation}

M2. It is well-known that DFT includes a certain amount of dynamic correlation and that topologies of KS-DFT densities usually overestimate QTAIM metrics because of inherent selfinteraction error. ${ }^{5}$ As it can be seen in Supplementary Table5, PBE0 densities indeed overestimate QTAIM metrics that are decreased when derived from a minimum CAS (two electrons in seven orbitals) wavefunction. This decrease occurs due to electron repulsion in the covalent region, where electron correlation allows the electron density to 'move out' of the interatomic region toward the atomic basins, while the opposite is true for ionic bonds. ${ }^{6}$ Furthermore, the addition of one of the imido lone pairs to the active space is essential to recover static correlation with the ligands because of significant orbital mixing. This is interesting because it is commonly accepted for low-valent actinide complexes that minimal active spaces suffice to properly describe the electron density of the system.

$\boldsymbol{U}(\boldsymbol{V I})(\mathrm{NPh})_{2} \boldsymbol{C l}_{2} \boldsymbol{T H F}_{2}$. Overall, and as expected, U(VI)-N $\mathrm{N}_{\text {imido }}$ bonds are more covalent than the other interactions of U(VI). This can be seen in the higher concentration of electron density in the interatomic regions and delocalization indices. From the energy density perspective, the total energy densities are impressively large when compared to the rest of the bonds (Supplementary Table6). The trans position displayed by the imido ligands allows comparisons to uranyl derivatives; however, the delocalization indices (electrons shared) describing the interaction between uranium(VI) and $\mathrm{O}_{\mathrm{yl}}$ atoms are close to 2 (from a CAS $(12,12)$ wavefunction), ${ }^{7}$ while for $\mathrm{N}_{\text {imido }}$ they are described as 1 . This difference may stem from the fact that the phenyl ring in $\mathrm{NPh}^{2-}$ allows for strong delocalization of the density localized in the $\mathrm{N}$ atom. In either case, the interaction is not described by a formal triple bond as indicated in the Lewis depiction of the chemical bond. It is remarkable that DFT supports this interaction as a double bond, which is corrected by static correlation (CASSCF) to a single bond in terms of pairs of electrons shared (Supplementary Table 6). This striking difference is also seen in the ellipticity of the bond, where DFT predicts $\varepsilon(\mathrm{r})$ close to zero, indicative of a purely cylindrical bond, while CASSCF suggests otherwise. It is interesting that values deviating from zero imply double bonds. In this case, the strong delocalization yields non-cylindrical bonds with the strength of a single bond. From another perspective, the covalent character of the bonds between U(VI)- $\mathrm{N}_{\text {imido }}$ obtained from the $|\mathrm{V}| / \mathrm{G}$ ratio predicts $48 \%$ of covalent character (partial covalent bond) in contrast to the $33 \%$ and $25 \%$ predicted for the U(IV)- $\mathrm{N}_{\text {imido }}$ bonds (Supplementary Table 5). This supports the idea that the covalent character is decreased in the tetravalent bis(imido) complex with respect to the hexavalent analog.

Ligand Field DFT. A final approach that provides a global description of covalency as described by Lever ${ }^{8}$ within the ligand-field theory, is the reduction of the interelectronic repulsion parameters of Slater-Condon $\mathrm{F}^{\mathrm{k}}(5 f, 5 f)(\mathrm{k}=0,2,4,6)$ and the effective spin-orbit coupling parameter $\zeta_{\mathrm{SO}}(5 f)$ to assess covalent interactions taking place within the $5 f$ shell. The coordination of imido and NTSA ligands induces an expansion of the $5 f$-electron cloud such that the electron repulsion is decreased to $\sim 60 \%$ and the effective spin-orbit coupling to $\sim 41 \%$ 
(Supplementary Table7), which is certainly unexpected for an actinide compound. ${ }^{9}$ This confirms the unsual effects of imido coordination to the $5 f$-shell of $\mathrm{U}(\mathrm{IV})$.

\section{Figures and Tables}

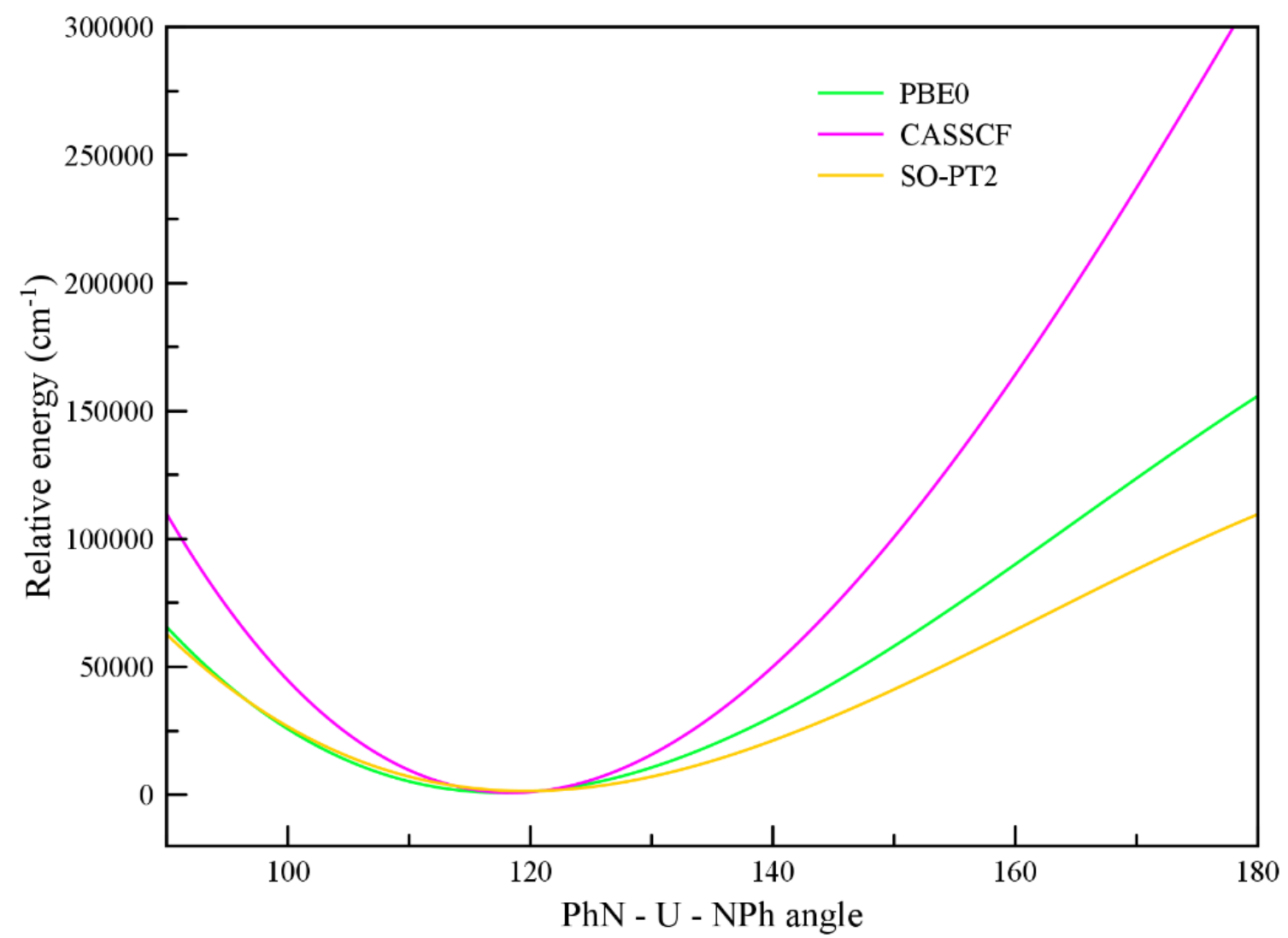

Supplementary Fig. 7. Potential energy surface resulting of varying the $\mathrm{N}_{\text {imido }}-\mathrm{U}^{\mathrm{IV}}-\mathrm{N}_{\text {imido }}$ angle. 


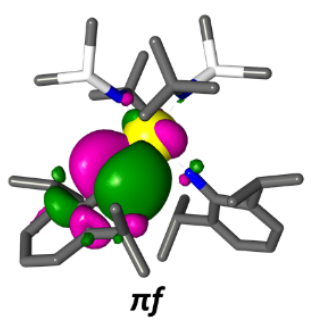

Occ $=1.58$

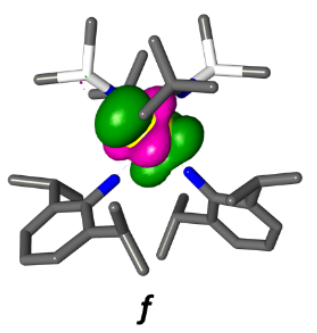

Occ $=0.72$

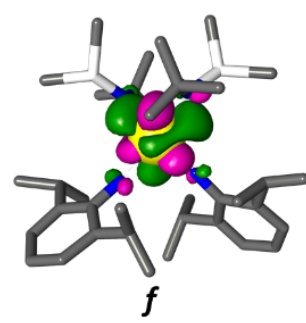

Occ $=0.14$

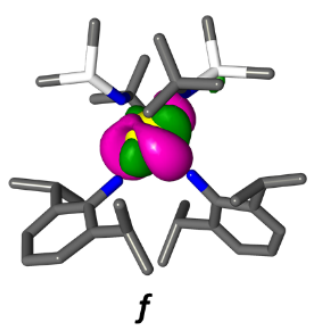

Occ $=0.05$

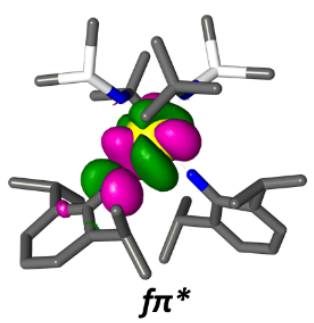

Occ $=0.31$

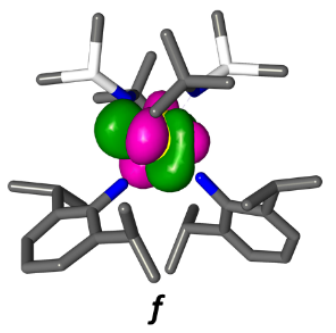

Occ $=0.14$

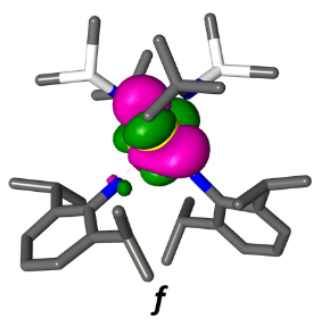

Occ $=0.76$

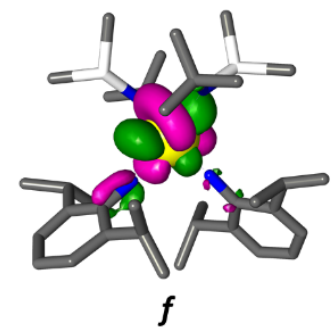

Occ $=0.13$

Supplementary Fig. 8. CASSCF Natural Orbitals of M2 system. The occupation numbers correspond to the ground state configuration. 
NLMO1c (4\% U)

$9 \% 7 s+2 \% 7 p+60 \% 6 d+30 \% 5 f$

$\mathrm{BO}=0.08 ;$ Hybrid Overlap $=0.24$

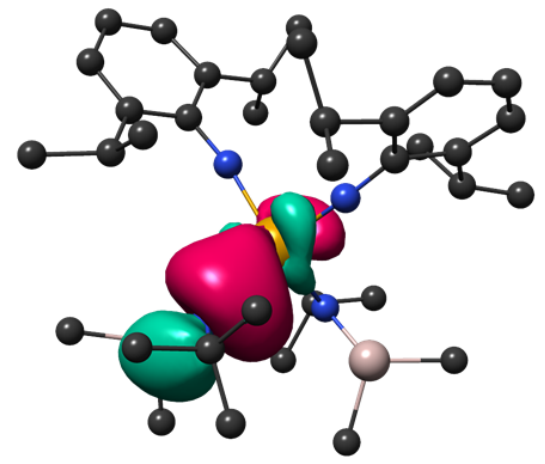

NLM01d (5\% U)

$10 \% 7 s+2 \% 7 p+60 \% 6 d+28 \% 5 f$

BO $=0.08 ;$ Hybrid Overlap $=0.24$

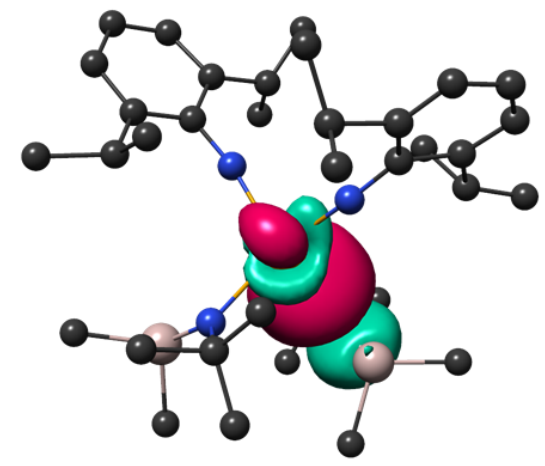

NLMO2c (4\% U)

$49 \% 6 d+51 \% 5 f$

$\mathrm{BO}=0.08 ;$ Hybrid Overlap $=0.50$

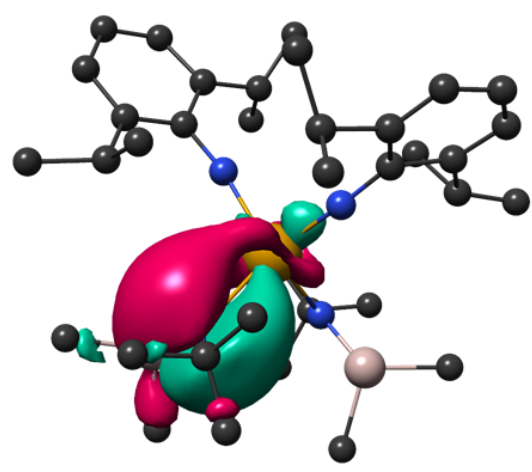

NLMO2d (4\% U)

$49 \% 6 d+51 \% 5 f$

BO $=0.08 ;$ Hybrid Overlap $=0.50$

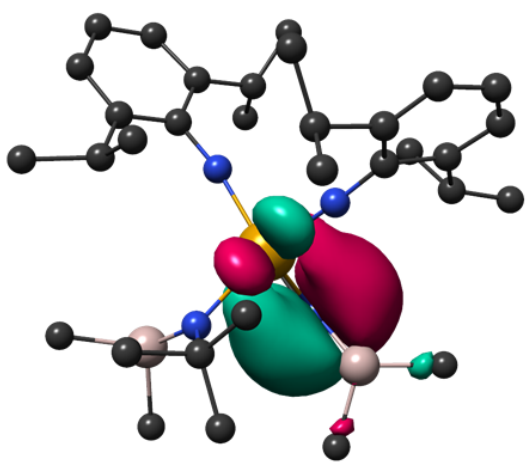

Supplementary Fig. 9. Natural localized molecular orbitals (NLMOs) describing bonding interactions between U(IV) and one of the NTSA ligands. U(IV) contribution to the NLMO and its composition are given. NLMO-based bond orders (BO), and their corresponding hybrid overlap are also given. 

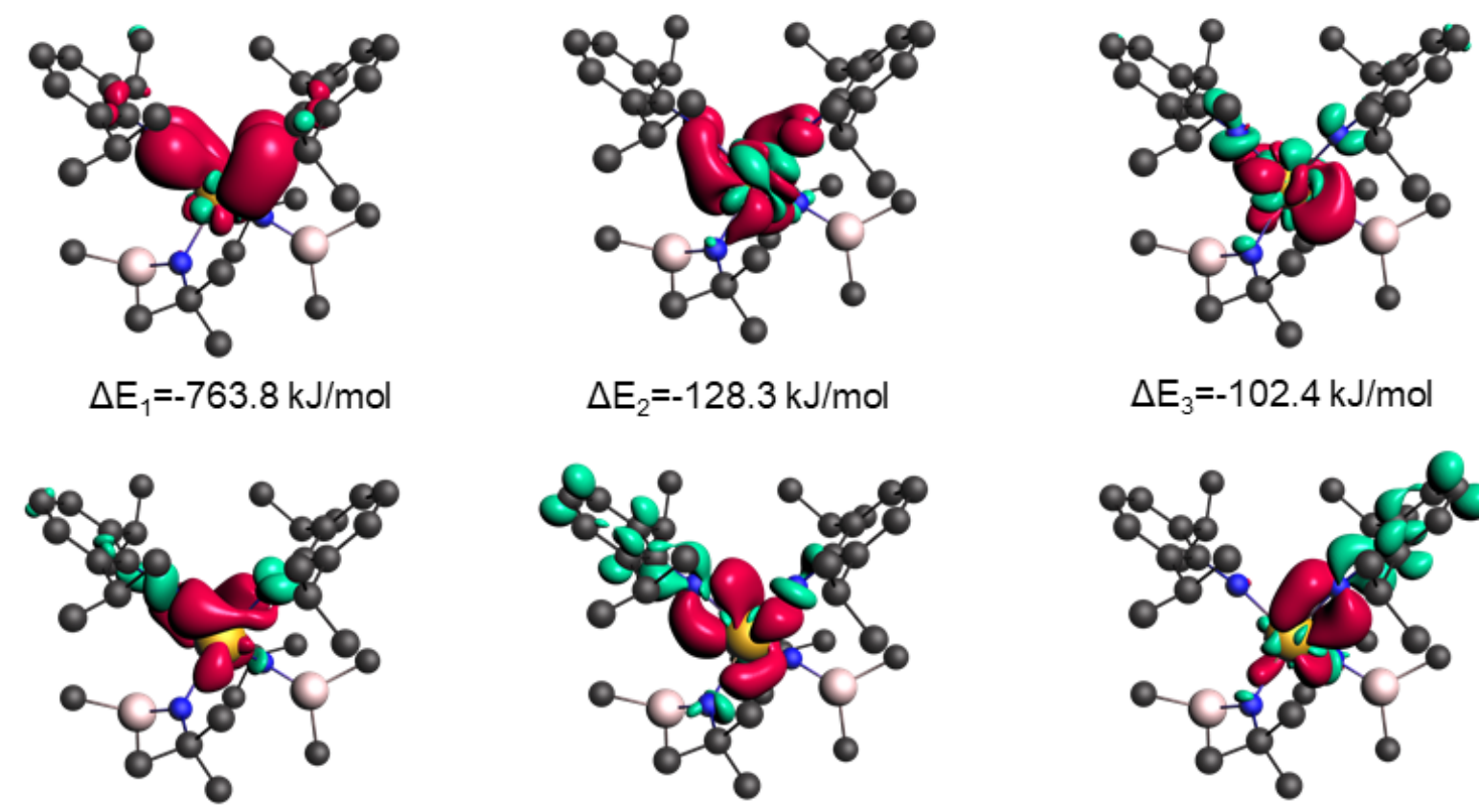

$$
\Delta \mathrm{E}_{2}=-128.3 \mathrm{~kJ} / \mathrm{mol}
$$

$$
\Delta \mathrm{E}_{3}=-102.4 \mathrm{~kJ} / \mathrm{mol}
$$

$$
\Delta \mathrm{E}_{4}=-240.4 \mathrm{~kJ} / \mathrm{mol}
$$
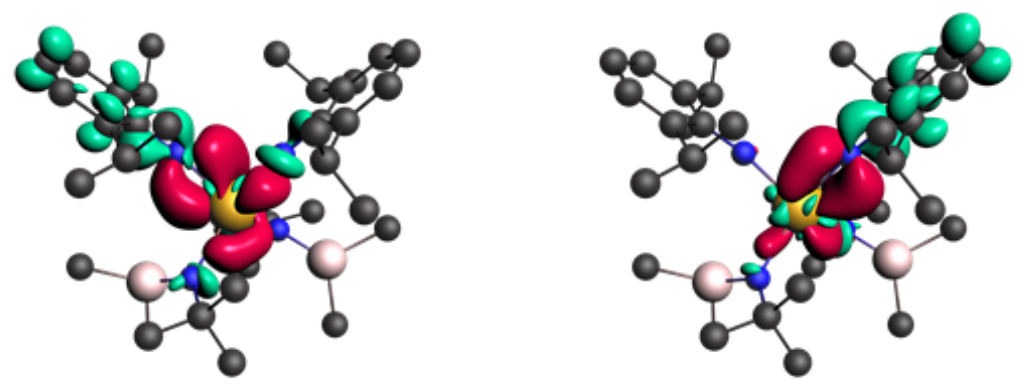

$$
\Delta \mathrm{E}_{5}=-228.9 \mathrm{~kJ} / \mathrm{mol}
$$

$$
\Delta E_{6}=-195.8 \mathrm{~kJ} / \mathrm{mol}
$$

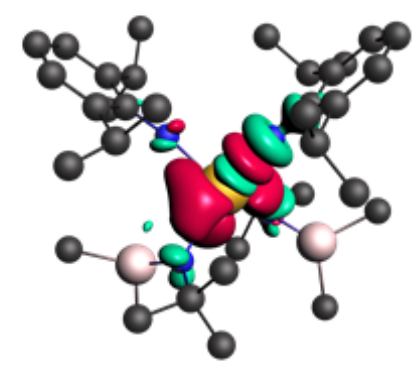

$$
\Delta \mathrm{E}_{7}=-185.4 \mathrm{~kJ} / \mathrm{mol}
$$
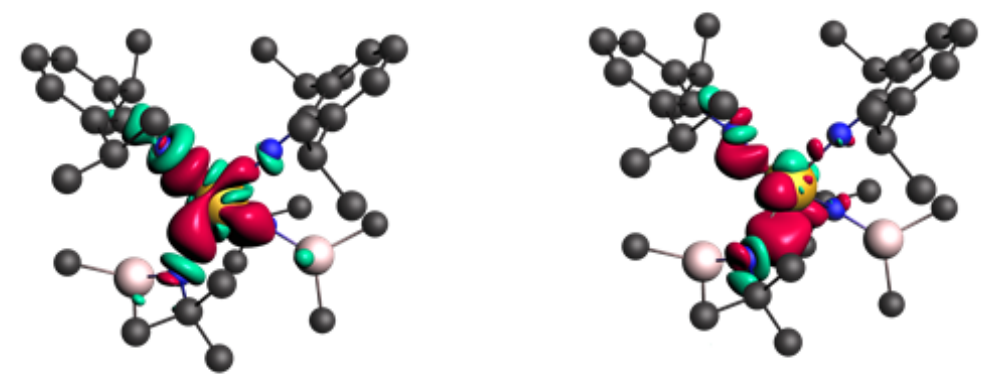

$$
\Delta \mathrm{E}_{8}=-159.9 \mathrm{~kJ} / \mathrm{mol}
$$

$\Delta \mathrm{E}_{9}=-103.6 \mathrm{~kJ} / \mathrm{mol}$

Supplementary Fig. 10. Deformation densities $\left(\Delta \rho_{\mathrm{i}}\right)$ and their corresponding energies of stabilization $\left(\Delta \mathrm{E}_{\mathrm{i}}\right)$ from the ETS-NOCV analysis performed under the KS-DFT formalism. The selected $\Delta \rho_{i}$ cover $40 \%$ of the total orbital interaction energy. Inflow and outflow densities are depicted in red and green surfaces, respectively. 


\begin{tabular}{|c|c|c|c|c|c|c|c|}
\hline ANGLE & \multicolumn{7}{|c|}{ NATURAL CASSCF ORBITALS } \\
\hline 95 & $\begin{array}{c}\mathbf{2} \% d \\
\mathbf{9 4 \% f} \\
\mathbf{3} \% \text { lig. } \\
\text { Occ }=0.05\end{array}$ & $\begin{array}{c}1 \% d \\
97 \% f \\
0 \% \text { lig. } \\
\text { Occ }=0.11\end{array}$ & $\begin{array}{c}\mathbf{5} \% d \\
\mathbf{9 4 \%} f \\
1 \% \text { lig. } \\
\text { Occ }=0.37\end{array}$ & $\begin{array}{c}1 \% d \\
96 \% f \\
1 \% \text { lig. } \\
\text { Occ }=0.51\end{array}$ & $\begin{array}{c}4 \% d \\
95 \% f \\
0 \% \text { lig. } \\
\text { Occ }=0.64\end{array}$ & $\begin{array}{c}2 \% d \\
92 \% f \\
2 \% \text { lig. } \\
\text { Occ }=0.23\end{array}$ & $\begin{array}{c}2 \% d \\
94 \% f \\
1 \% \text { lig. } \\
\text { Occ }=0.09\end{array}$ \\
\hline 105 & $\begin{array}{c}1 \% d \\
97 \% f \\
1 \% \text { lig. } \\
\text { Occ }=0.21\end{array}$ & $\begin{array}{c}3 \% d \\
96 \% f \\
0 \% \text { lig. } \\
\text { Occ }=0.69\end{array}$ & $\begin{array}{c}2 \% d \\
95 \% f \\
1 \% \text { lig. } \\
\text { Occ }=0.33\end{array}$ & $\begin{array}{c}\mathbf{2} \% d \\
\mathbf{9 3} \% f \\
\mathbf{3} \% \text { lig. } \\
\text { Occ }=0.06\end{array}$ & $\begin{array}{c}3 \% d \\
95 \% f \\
1 \% \text { lig. } \\
\text { Occ }=0.12\end{array}$ & $\begin{array}{c}1 \% d \\
94 \% f \\
1 \% \text { lig. } \\
\text { Occ }=0.28\end{array}$ & $\begin{array}{c}2 \% d \\
94 \% f \\
2 \% \text { lig. } \\
\text { Occ }=0.29\end{array}$ \\
\hline 110 & $\begin{array}{c}95 \% f \\
2 \% \text { lig. } \\
\text { Occ }=0.28\end{array}$ & $\begin{array}{c}96 \% f \\
0 \% \text { lig. } \\
\text { Occ }=0.65\end{array}$ & $\begin{array}{c}97 \% f \\
1 \% \text { lig. } \\
\text { Occ }=0.36\end{array}$ & $\begin{array}{c}94 \% f \\
2 \% \text { lig. } \\
\text { Occ }=0.11\end{array}$ & $\begin{array}{c}93 \% f \\
1 \% \text { lig. } \\
\text { Occ }=0.15\end{array}$ & $\begin{array}{c}\mathbf{9 4 \%} f \\
\mathbf{2 \%} \text { lig. } \\
\text { Occ }=0.13\end{array}$ & $\begin{array}{c}95 \% f \\
1 \% \text { lig. } \\
\text { Occ }=0.31\end{array}$ \\
\hline 115 & $\begin{array}{c}0 \% d \\
96 \% f \\
1 \% \text { lig. } \\
\text { Occ }=0.39\end{array}$ & $\begin{array}{c}2 \% d \\
96 \% f \\
1 \% \text { lig. } \\
\text { Occ }=0.25\end{array}$ & $\begin{array}{c}0 \% d \\
94 \% f \\
3 \% \text { lig. } \\
\text { Occ }=0.09\end{array}$ & $\begin{array}{c}\mathbf{2 \% d} d \\
\mathbf{9 4 \%} f \\
\mathbf{2 \%} \text { lig. } \\
\text { Occ }=0.30\end{array}$ & $\begin{array}{c}2 \% d \\
95 \% f \\
1 \% \text { lig. } \\
\text { Occ }=0.31\end{array}$ & $\begin{array}{c}\mathbf{2} \% d \\
\mathbf{9 7 \%} f \\
0 \% \text { lig. } \\
\text { Occ }=0.44\end{array}$ & $\begin{array}{c}3 \% d \\
95 \% f \\
1 \% \text { lig. } \\
\text { Occ }=0.51\end{array}$ \\
\hline 120 & $\begin{array}{c}2 \% d \\
93 \% f \\
2 \% \text { lig. } \\
\text { Occ }=0.10\end{array}$ & $\begin{array}{c}1 \% d \\
95 \% f \\
1 \% \text { lig. } \\
\text { Occ }=0.28\end{array}$ & $\begin{array}{c}2 \% d \\
96 \% f \\
1 \% \text { lig. } \\
\text { Occ }=0.34\end{array}$ & $\begin{array}{c}2 \% d \\
95 \% f \\
1 \% \text { lig. } \\
\text { Occ }=0.22\end{array}$ & $\begin{array}{c}0 \% d \\
93 \% f \\
4 \% \text { lig. } \\
\text { Occ }=0.02\end{array}$ & $\begin{array}{c}3 \% d \\
96 \% f \\
0 \% \text { lig. } \\
\text { Occ }=0.64\end{array}$ & $\begin{array}{c}1 \% d \\
97 \% f \\
1 \% \text { lig. } \\
\text { Occ }=0.37\end{array}$ \\
\hline 125 & $\begin{array}{c}1 \% d \\
95 \% f \\
2 \% \text { lig. } \\
\text { Occ }=0.23\end{array}$ & $\begin{array}{c}94 \% f \\
2 \% \text { lig. } \\
\text { Occ }=0.14\end{array}$ & $\begin{array}{c}2 \% d \\
95 \% f \\
1 \% \text { lig. } \\
\text { Occ }=0.20\end{array}$ & $\begin{array}{c}\mathbf{2 \% d} d \\
\mathbf{9 7 \%} f \\
\mathbf{0 \%} \text { lig. } \\
\text { Occ }=0.32\end{array}$ & $\begin{array}{c}2 \% d \\
96 \% f \\
1 \% \text { lig. } \\
\text { Occ }=0.45\end{array}$ & $\begin{array}{c}1 \% d \\
96 \% f \\
0 \% \text { lig. } \\
\text { Occ }=0.54\end{array}$ & $\begin{array}{c}1 \% d \\
93 \% f \\
2 \% \text { lig. } \\
\text { Occ }=0.13\end{array}$ \\
\hline
\end{tabular}




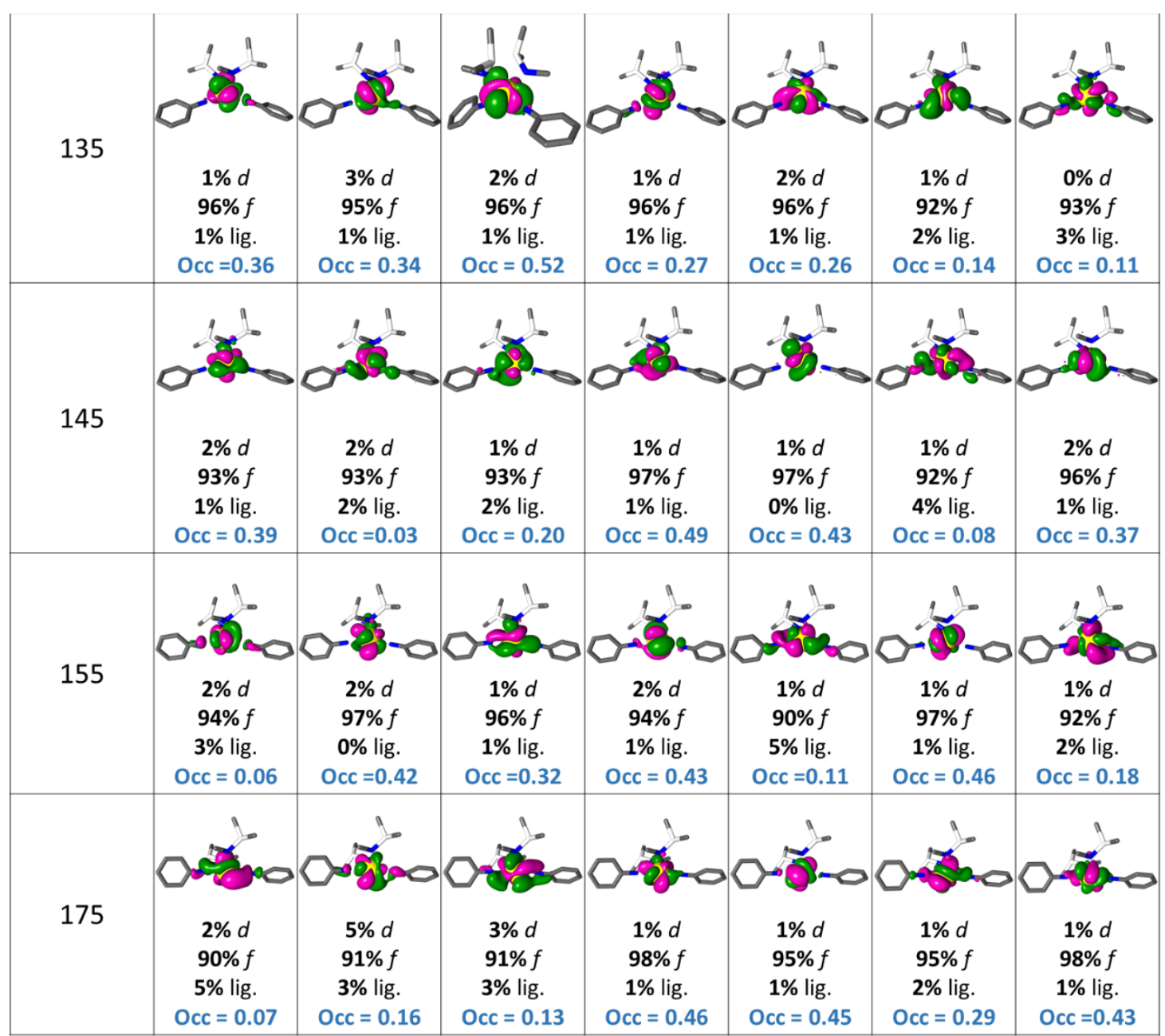

Supplementary Fig. 11. Natural CASSCF orbitals for every single system calculated to build the PES. Occupation numbers correspond to the ground state. 
Supplementary Table 4. Comparison of selected experimental and theoretical geometry parameters.

\begin{tabular}{llllll}
\hline & Exp & $\mathrm{M}^{\mathrm{a}}$ & $\mathrm{M} 2^{\mathrm{b}}$ & $\mathrm{M}^{\mathrm{c}}$ & $\mathrm{M}^{\mathrm{d}}$ \\
\cline { 2 - 6 } $\mathrm{U}^{\mathrm{IV}}-\mathrm{N}_{\text {imido }}$ & $2.069(17)$ & 2.133 & 2.089 & 2.083 & 1.942 \\
$\mathrm{U}^{\mathrm{IV}}-\mathrm{N}_{\text {imido }}$ & $2.149(11)$ & 2.133 & 2.095 & 2.090 & 1.941 \\
$\mathrm{U}^{\mathrm{IV}}-\mathrm{NTSA}$ & $2.365(12)$ & 2.403 & 2.471 & 2.377 & - \\
$\mathrm{U}^{\mathrm{IV}}-\mathrm{NTSA}$ & $2.365(14)$ & 2.404 & 2.481 & 2.388 & - \\
$\mathrm{U}^{\mathrm{IV}}-\mathrm{K}^{+}$ & $3.7617(12)$ & 3.7842 & - & - & - \\
$\mathrm{N}_{\text {imido }}-\mathrm{U}^{\mathrm{IV}}-\mathrm{N}_{\text {imido }}$ & $95.2(3)$ & 93.0 & 102.8 & 115.1 & 118.6 \\
\hline
\end{tabular}


Supplementary Table 5. Morokuma-Ziegler energy decomposition analysis of the interaction between $\mathrm{U}^{\mathrm{IV}}$ and the ligand environment in $\mathbf{1}$.

\begin{tabular}{ll}
\hline \multicolumn{1}{c}{ Component } & $\mathrm{eV}$ \\
\hline Electrostatic & -89.1 \\
Pauli & 24.4 \\
Steric & -64.7 \\
Orbital & -53.3 \\
Total & -118.0 \\
\hline
\end{tabular}


Supplementary Table 6. QTAIM metrics derived from KS-DFT and SR-CASSCF densities of M2. Electron densities are given in $|\mathrm{e}| \AA^{-3}$, and potential $\mathrm{V}$, kinetic $\mathrm{G}$, and total $\mathrm{H}$ energy densities given in $\mathrm{kJ} \mathrm{mol}^{-1} \AA^{-3}$.

\begin{tabular}{|c|c|c|c|c|c|c|c|c|}
\hline Wavefunction & Bond & $\rho(\mathrm{r})$ & $\delta(\mathrm{r})$ & $\mathrm{V}(\mathrm{r})$ & $\mathrm{G}(\mathrm{r})$ & $\mathrm{H}(\mathrm{r})$ & $|\mathrm{V}| / \mathrm{G}$ & $\varepsilon(\mathrm{r})$ \\
\hline PBE0 & \multirow{3}{*}{ 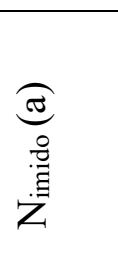 } & 0.9913 & 1.2335 & -3989.9 & 2874.0 & -1115.9 & 1.39 & 0.1137 \\
\hline $\operatorname{CAS}(2,7)$ & & 0.9137 & 0.9275 & -3856.5 & 2852.9 & -1003.6 & 1.35 & 0.1701 \\
\hline $\operatorname{CAS}(4,8)$ & & 0.8908 & 0.8822 & -3793.4 & 2844.2 & -949.2 & 1.33 & 0.1206 \\
\hline PBE0 & \multirow{3}{*}{ 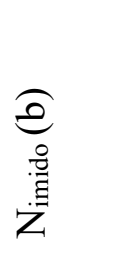 } & 0.8388 & 1.1660 & -3140.7 & 2354.6 & -786.0 & 1.33 & 0.1688 \\
\hline $\operatorname{CAS}(2,7)$ & & 0.7700 & 0.8589 & -3040.7 & 2344.1 & -696.6 & 1.30 & 0.1669 \\
\hline $\operatorname{CAS}(4,8)$ & & 0.7389 & 0.6316 & -3028.4 & 2431.8 & -596.6 & 1.25 & 0.0215 \\
\hline PBE0 & \multirow{3}{*}{$\begin{array}{l}\text { êt } \\
\overleftarrow{\Delta} \\
\stackrel{\Delta}{Z} \\
z\end{array}$} & 0.5790 & 0.5979 & -1719.5 & 1333.5 & -386.0 & 1.29 & 0.1738 \\
\hline $\operatorname{CAS}(2,7)$ & & 0.5351 & 0.4716 & -1721.2 & 1398.4 & -322.8 & 1.23 & 0.1651 \\
\hline $\operatorname{CAS}(4,8)$ & & 0.5162 & 0.4798 & -1701.9 & 1410.7 & -291.3 & 1.21 & 0.0969 \\
\hline PBE0 & \multirow{3}{*}{ 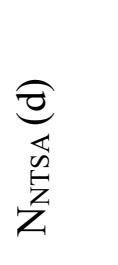 } & 0.5743 & 0.6136 & -1682.6 & 1298.4 & -384.3 & 1.30 & 0.216 \\
\hline $\operatorname{CAS}(2,7)$ & & 0.5318 & 0.4818 & -1691.4 & 1366.8 & -324.6 & 1.24 & 0.1955 \\
\hline $\operatorname{CAS}(4,8)$ & & 0.5122 & 0.4761 & -1666.8 & 1377.3 & -289.5 & 1.21 & 0.1652 \\
\hline
\end{tabular}


Supplementary Table 7. QTAIM metrics derived from KS-DFT and SR-CASSCF densities of $\mathbf{U}(\mathbf{V I})(\mathbf{N P h})_{2} \mathbf{C l}_{2} \mathbf{T H F}$. Electron densities are given in $|\mathrm{e}| \AA^{-3}$, and potential $\mathrm{V}$, kinetic $\mathrm{G}$, and total $\mathrm{H}$ energy densities given in $\mathrm{kJ}^{\mathrm{mol}}{ }^{-1} \AA^{-3}$.

\begin{tabular}{|c|c|c|c|c|c|c|c|c|}
\hline Wavefunction & Bond & $\rho(\mathrm{r})$ & $\delta(\mathrm{r})$ & $\mathrm{V}(\mathrm{r})$ & $G(r)$ & $\mathrm{H}(\mathrm{r})$ & $|\mathrm{V}| / \mathrm{G}$ & $\varepsilon(\mathrm{r})$ \\
\hline PBE0 & 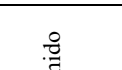 & 1.3851 & 1.8368 & -6352.0 & 4060.3 & -2291.7 & -1.56 & 0.0462 \\
\hline $\operatorname{CAS}(8,12)$ & 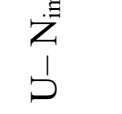 & 1.2673 & 1.0043 & -6224.0 & 4207.1 & -2016.9 & -1.48 & 0.1933 \\
\hline PBE0 & : & 1.3849 & 1.8377 & -6364.1 & 4072.2 & -2292.0 & -1.56 & 0.0392 \\
\hline $\operatorname{CAS}(8,12)$ & $\begin{array}{l}z \\
\text { z } \\
b\end{array}$ & 1.2687 & 0.9996 & -6219.5 & 4197.9 & -2021.6 & -1.48 & 0.2179 \\
\hline PBE0 & $F$ & 0.4595 & 0.6955 & -1160.3 & 916.2 & -244.1 & -1.27 & 0.0382 \\
\hline $\operatorname{CAS}(8,12)$ & b & 0.4249 & 0.4491 & -1216.4 & 1020.7 & -195.7 & -1.19 & 0.0319 \\
\hline PBE0 & & 0.4574 & 0.6876 & -1151.8 & 910.4 & -241.5 & -1.27 & 0.0470 \\
\hline $\operatorname{CAS}(8,12)$ & b & 0.4230 & 0.4447 & -1208.5 & 1015.1 & -193.4 & -1.19 & 0.0314 \\
\hline PBE0 & 地 & 0.3469 & 0.2776 & -991.2 & 970.2 & -21.0 & -1.02 & 0.1419 \\
\hline $\operatorname{CAS}(8,12)$ & $\begin{array}{l}0 \\
1 \\
0\end{array}$ & 0.3328 & 0.2181 & -1037.4 & 1034.3 & -3.1 & -1.00 & 0.1070 \\
\hline PBE0 & 崖 & 0.3458 & 0.2750 & -984.2 & 963.5 & -20.7 & -1.02 & 0.1484 \\
\hline $\operatorname{CAS}(8,12)$ & $\begin{array}{l}0 \\
1 \\
0\end{array}$ & 0.3965 & 0.2176 & -1030.9 & 1028.6 & -2.4 & -1.00 & 0.1199 \\
\hline
\end{tabular}


Supplementary Table 8. Slater-Condon $\mathrm{F}^{\mathrm{k}}(\mathrm{k}=0,2,4,6)$ and effective spin-orbit coupling $\zeta_{\text {so }}$ parameters of the $5 f$ electrons calculated from LF-DFT for the free and complexed $\mathrm{U}^{\mathrm{IV}}$ ion.

\begin{tabular}{cccc}
\hline Parameter & $\mathrm{U}_{\text {free-ion }}$ & Complex 1 & Reduction \\
\hline $\mathrm{F}^{0}(5 f, 5 f)$ & 17.4418 & 6.9874 & $59.94 \%$ \\
$\mathrm{~F}^{2}(5 f, 5 f)$ & 8.7422 & 3.3862 & $61.27 \%$ \\
$\mathrm{~F}^{4}(5 f, 5 f)$ & 5.7021 & 2.1807 & $61.76 \%$ \\
$\mathrm{~F}^{6}(5 f, 5 f)$ & 4.1805 & 1.5902 & $61.96 \%$ \\
$\zeta_{\text {SO }}(5 f)$ & 0.2477 & 0.1455 & $41.26 \%$ \\
\hline
\end{tabular}


Supplementary Table 9. Ground state splitting for the ten systems used to build the PES. Results are given in wavenumbers $\left(\mathrm{cm}^{-1}\right)$.

\begin{tabular}{cccc}
\hline Angle & CASSCF & SO-CASSCF & SO-PT2 \\
\hline 95 & 2313.1 & 1673.6 & 1504.1 \\
105 & 2359.3 & 1819.6 & 1589.8 \\
110 & 2515.8 & 2009.7 & 1671.6 \\
115 & 2594.3 & 2072.3 & 1680.6 \\
120 & 2801.5 & 2256.9 & 1771.8 \\
125 & 2941.8 & 2310.6 & 1826.1 \\
135 & 3647.5 & 2939.6 & 2229.5 \\
145 & 4283 & 3480.3 & 2599.1 \\
155 & 4948.6 & 4060.1 & 2998.4 \\
175 & 6060.8 & 5016.5 & 3832.4 \\
\hline
\end{tabular}




\section{References}

[1] Bruker (2016), Apex3 v2016.9-0, Saint V8.37A, Bruker AXS Inc.: Madison (WI), USA, 2013/2014.

[2] a) SHELXTL suite of programs, Version 6.14, 2000-2003, Bruker Advanced X-ray Solutions, Bruker AXS Inc., Madison, Wisconsin: USA b) Sheldrick, G.M. A short history of SHELX. Acta Crystallogr A., 64(1), 112-122 (2008).

[3] a) Sheldrick, G.M. University of Göttingen, Germany, 2018. b) Sheldrick, G.M. Crystal structure refinement with SHELXL. Acta Crystallogr Sect C Struct Chem., 71(1), 3-8 (2015).

[4] Hübschle, C.B., Sheldrick, G.M., Dittrich, B. ShelXle: a Qt graphical user interface for SHELXL. J. Appl. Crystallogr., 44(6), 1281-1284 (2011).

[5] Kerridge, A. Quantification of f-element covalency through analysis of the electron density: insights from simulation. Chem. Comm. 53(50), 6685-6695 (2017).

[6] Silva, A.F.; Duarte, L.J.; Popelier, P.L.A. Contributions of IQA electron correlation in understanding the chemical bond and non-covalent interactions. Struct. Chem. 31, 507519 (2020).

[7] Fryer-Kanssen, I. \& Kerridge, A. Elucidation of the inverse trans influence in uranyl and its imido and carbene analogues via quantum chemical simulation. Chem. Comm., 54(70), 9761-9764 (2018).

[8] Lever, A. B. P. Inorganic Electronic Spectroscopy (Elsevier Publisher Company, 1968).

[9] Jung, J.; Atanasov, M.; Neese, F. Ab initio ligand-field theory analysis and covalency trends in actinide and lanthanide free ions and octahedral complexes. Inorg. Chem., 56(15), 8802-8816 (2017). 